\title{
European Union emissions trading scheme impact on the Spanish electricity price during phase II and phase III implementation
}

\author{
Carlos J. Pereira Freitas a , Patrícia Pereira da Silva b, c, * \\ a Institute of Engineering, Polytechnic of Porto (ISEP), Rua Dr. António Bernardino de Almeida, 431, 4200-072 Porto, Portugal \\ ${ }^{\mathrm{b}}$ Faculty of Economics, University of Coimbra, Av. Dias da Silva, 165, 3004-512 Coimbra, Portugal \\ ${ }^{\mathrm{c}}$ Institute for Systems Engineering and Computers at Coimbra (INESCC), Rua Antero de Quental, 199, 3000-030 Coimbra, Portugal
}

\section{A R T I C L E I N F O}

\section{Article history:}

Received 13 May 2014

Received in revised form

26 January 2015

Accepted 26 January 2015

Available online 7 March 2015

\section{JEL codes:}

Q58

$\mathrm{H} 23$

Q48

C32

L94

Keywords:

Environmental policy

Carbon emissions

Electricity prices

Cointegration

Vector error correction mode

\begin{abstract}
A B S T R A C T
The European Union Emissions Trading Scheme (EU ETS) is a cornerstone of the European Union's policy to combat climate change and its key tool for reducing industrial greenhouse gas emissions costeffectively. The purpose of the present work is to evaluate the influence of $\mathrm{CO}_{2}$ opportunity cost on the Spanish wholesale electricity price. Our sample includes all Phase II of the EU ETS and the first year of Phase III implementation, from January 2008 to December 2013. A vector error correction model (VECM) is applied to estimate not only long-run equilibrium relations, but also short-run interactions between the electricity price and the fuel (natural gas and coal) and carbon prices. The four commodities prices are modeled as joint endogenous variables with air temperature and renewable energy as exogenous variables. We found a long-run relationship (cointegration) between electricity price, carbon price, and fuel prices. By estimating the dynamic pass-through of carbon price into electricity price for different periods of our sample, it is possible to observe the weakening of the link between carbon and electricity prices as a result from the collapse on $\mathrm{CO}_{2}$ prices, therefore compromising the efficacy of the system to reach proposed environmental goals. This conclusion is in line with the need to shape new policies within the framework of the EU ETS that prevent excessive low prices for carbon over extended periods of time.
\end{abstract}

(c) 2015 Elsevier Ltd. All rights reserved.

\section{Introduction}

The European Union Emissions Trading Scheme (EU ETS) is the first international system for trading greenhouse gas emission allowances. The EU ETS works based on the 'cap-and-trade' principle. Among the several industries covered by the scheme, the electricity sector is the largest one. Launched in 2005, implementation of the EU ETS was set to run in three phases: the first (pilot phase) ranging from 2005 to 2007, the second from 2008 to 2012 and now in its third phase, running from 2013 to 2020 . Economic theory explains why under a 'cap-and-trade' system, the price of emissions ought to be treated as a marginal cost. As a producer holds allowances, the electricity production and $\mathrm{CO}_{2}$ emission compete with the possibility of selling those allowances in the market. Therefore,

\footnotetext{
* Corresponding author. Faculty of Economics, University of Coimbra, Av. Dias da Silva, 165, 3004-512 Coimbra, Portugal.
}

E-mail addresses: cpf@isep.ipp.pt (C.J.P. Freitas), patsilva@fe.uc.pt (P.P. Silva). according to the economic theory, energy producers are expected to add this new cost to their marginal production cost whether or not $\mathrm{CO}_{2}$ allowances are granted for free. This so-called $\mathrm{CO}_{2}$ opportunity cost equals the $\mathrm{CO}_{2}$ market price. Adding the opportunity cost of carbon to the other costs of energy generation and passing these costs through to the electricity price is a necessary condition for achieving the environmental targets in a cost-efficient way (that is, guaranteeing that the emission cuts would be made by those firms that could achieve the most efficient abatement costs).

Thus, the efficiency of the EU ETS in providing incentives both to the energy producers (to reduce their emissions by switching to or investing in technologies with lower emissions) and energy consumers (to reduce their demand of electricity by increasing their energy efficiency) depends on whether or not $\mathrm{CO}_{2}$ costs may be passed through to electricity prices. We therefore investigate as our research problem the interaction between the electricity markets and carbon markets trying to find out how the EU ETS impacts the price of electricity. Our specific research questions are: Does the carbon price have an impact on the Spanish electricity price? Do the 
prices of electricity and carbon (and other fuels used in electricity generation) share a common trend?

The theoretical foundation of the $\mathrm{CO}_{2}$ cost pass-through to electricity prices is well established in the scientific literature, as presented by Sijm et al. (2006) in the context of perfect competition, and by Bonacina and Gulli (2007) for markets under imperfect competition. While electricity producers may fully recognize the opportunity costs of $\mathrm{CO}_{2}$ allowances in their marginal production costs, these costs might not be fully passed through to electricity prices. Sijm et al. (2005) and Gullì (2008) offer a set of explanations for the pass-through rate of $\mathrm{CO}_{2}$ costs into electricity prices that may differ by $100 \%$, including among other reasons demand response (price elasticity), level of energy demand (peak-load vs. off-peak-load), market structure (degree of market concentration), technology mix (fuel used in production), and available generation capacity.

This paper builds on previous work by the authors for the Portuguese Electricity Market (Freitas and Silva, 2013, 2012) on the complementary division of Iberian Electricity Market (MIBEL). According to our knowledge, we believe this study is an innovative contribution to the state of the art due to the fact that our research embodies the first empirical study of the Spanish market for the complete Phase II of the EU ETS, as well as the first empirical study on the European market to include results from the Phase III of the system. Moreover, the econometric treatment given to renewable energy within the model alongside carbon and fuel prices represents an important contribution considering the growing significance of these technologies in the Spanish energy mix. This paper is structured as follows. Section 2 presents a brief literature review. Section 3 describes the functioning of the Spanish electricity market and presents the data set. Section 4 describes the methodological approach. Section 5 presents the empirical findings. Section 6 concludes.

\section{Literature review}

Previous authors began to assess the interaction between carbon prices and electricity prices. A more extensive literature review regarding the EU ETS impact in the European power sector can be found in Freitas and Silva (2013). Initial published analyses conducted in order to estimate the pass-through rate of $\mathrm{CO}_{2}$ cost into electricity prices have not considered the mutual interactions between electricity price, fuel prices (natural gas, coal, fuel, oil), and carbon prices. The first studies taking those interdependencies into account through multivariate analysis, where all prices are modeled as a joint system, were provided by Honkatukia et al. (2006) and Fezzi and Bunn (2009). Developing a Vector Error Correction Model (VECM), with the electricity, gas and carbon prices modeled jointly as endogenous variables, and temperature as an exogenous regressor, Fezzi and Bunn (2009) estimated the dynamic pass-through of $\mathrm{CO}_{2}$ price into electricity price for Germany and the UK. Honkatukia et al. (2006) developed a similar model for the NordPool market considering the electricity, gas, coal, and carbon prices as endogenous variables. Other studies, including this one, have followed that econometric approach. Fell (2010), also for the NordPool and with the same prices variables, added to the VECM the temperature and the reservoir water level as exogenous regressor. Thoenes (2011) analyzed the relationship among electricity, fuels, and carbon prices for the German market, also with a VECM. Honkatukia et al. (2006), Fezzi and Bunn (2009), Fell (2010), Thoenes (2011), and Freitas and Silva (2013) found a long-run cointegrating equilibrium among electricity, fuels, and carbon prices. Chemarin et al. (2008) estimated a VECM to the French energy market considering electricity, gas, oil, and carbon prices as endogenous and two different weather variables: temperature (affecting the demand side of electricity market) and rainfall (influencing the electricity production of a country concerning its energy mix). The authors found that there is no short-run relationship between electricity returns and carbon returns, while there is a long-run relationship. Pinho and Madaleno (2011) examine the interactions between carbon, electricity, and fossil fuel (coal, oil, and natural gas) returns for Germany, France, and Nordic countries. They analyzed the effect of nuclear power generation using a VECM and found it could limit increases in electricity prices as a result of increased carbon prices.

Mohammadi (2009) analyzes the relation between the electricity prices and coal, natural gas, and crude oil prices for the United States (US) market finding, a long-run relationship between electricity and coal prices. Also for the US market, Mjelde and Bessler (2009) added the uranium price to the analysis and controlled for weather effects with temperature variables similar to those used in our model. They concluded that in the long run the price of electricity is influenced by the fuels market as these prices are weakly exogenous, except for uranium. Ferkingstad et al. (2011), for the Northern European electricity markets, studied the dynamics between electricity and fuel prices (oil, natural gas, and coal) with wind power and water reservoir level as exogenous variables. Using a VECM and a Linear non-Gaussian Acyclic Model (LinGAM), they concluded that in the long run, electricity and natural gas prices are interlinked. Moutinho et al. (2011) focused the Spanish power market, same as our study, but for an earlier period (2002-2005). Based on a cointegration approach, they concluded that electricity price is explained by the evolution of natural gas prices.

Cotton and Mello (2014) analyzed the efficiency of the Australian Emission Trading Scheme using a long-run structural modeling technique. They applied a generalized forecast error variance decomposition, finding that emissions prices have little effect on electricity prices.

Jouvet and Solier (2013) used a first order autoregressive model to assess the cost pass-through of $\mathrm{CO}_{2}$ into electricity prices. Their results indicated that while energy producers pass through the carbon cost during Phase I, the relationship between $\mathrm{CO}_{2}$ costs and marginal costs of electricity seems to be less evident over the second phase due to the global financial crises. Aatola et al. (2013), for a set of European countries, concluded that the carbon price has a positive but uneven impact on electricity prices. Boersen and Scholtens (2014), employing a Generalized Autoregressive Conditional Heteroskedasticity (GARCH) model concluded, for the NordPool market, that the price of electricity is partly determined by the cost of the fuel inputs (natural gas and oil prices) and these costs are affected by EUA prices.

With respect to the recent behavior of the carbon market and impacts on the electricity sector the recent works of Van den Bergh et al. (2013), Fagiani et al. (2014) and Koch et al. (2014) identified a set of reasons that might explain the $\mathrm{CO}_{2}$ price fall observed in recent years. These factors include economic recession, renewable policies and the use of international green certificates. Also, the impact of new developments in energy commodities markets on the price of $\mathrm{CO}_{2}$, namely the availability of cheap gas (shale gas), has been emphasized by some authors (Glachant and Ruester, 2014).

\section{Spanish electricity market and data}

The Spanish energy sector was liberalized in the late 1990s and the Spanish electricity wholesale market was established in 1998. An important reform implemented in the Iberian wholesale electricity markets was the launch of MIBEL in July 2007. The joint Portuguese-Spanish electricity market allows participants to trade power on either side of the border. The daily spot market (the drive 
Table 1

Electricity production and generation capacity by technology.

\begin{tabular}{|c|c|c|c|c|c|c|c|c|}
\hline \multirow[b]{3}{*}{ Nuclear } & \multicolumn{4}{|c|}{ Installed capacity (MW) } & \multicolumn{4}{|c|}{ Electricity production (GWh) } \\
\hline & \multicolumn{2}{|l|}{2008} & \multicolumn{2}{|l|}{2012} & \multicolumn{2}{|l|}{2008} & \multicolumn{2}{|l|}{2012} \\
\hline & 7716 & $8.5 \%$ & 7853 & $7.7 \%$ & 58,973 & $21.2 \%$ & 61,470 & $22.9 \%$ \\
\hline Hydroelectric & 16,657 & $18.3 \%$ & 17,761 & $17.4 \%$ & 21,428 & $7.7 \%$ & 19,455 & $7.2 \%$ \\
\hline Thermal fuel/gas & 4418 & $4.9 \%$ & 520 & $0.5 \%$ & 2378 & $0.9 \%$ & 0 & $0.0 \%$ \\
\hline Thermal coal & 11,359 & $12.5 \%$ & 11,248 & $11.0 \%$ & 46,275 & $16.6 \%$ & 54,721 & $20.4 \%$ \\
\hline CCGT (natural gas) & 21,675 & $23.9 \%$ & 25,340 & $24.9 \%$ & 91,286 & $32.8 \%$ & 38,593 & $14.4 \%$ \\
\hline Total ordinary regime & 61,825 & $68.0 \%$ & 62,722 & $61.6 \%$ & 220,340 & $79.2 \%$ & 174,239 & $64.9 \%$ \\
\hline Wind & 15,874 & $17.5 \%$ & 22,573 & $22.2 \%$ & 31,393 & $11.3 \%$ & 48,103 & $17.9 \%$ \\
\hline Other renewables & 6048 & $6.7 \%$ & 9293 & $9.1 \%$ & 11,599 & $4.2 \%$ & 20,608 & $7.7 \%$ \\
\hline Other non-renewables & 7132 & $7.8 \%$ & 7240 & $7.1 \%$ & 23,308 & $8.4 \%$ & 33,442 & $12.5 \%$ \\
\hline Total special regime & 29,054 & $32.0 \%$ & 39,106 & $38.4 \%$ & 66,300 & $23.8 \%$ & 102,153 & $38.0 \%$ \\
\hline Generation consumption & & & & & -8338 & $-3.0 \%$ & -7889 & $-2.9 \%$ \\
\hline Total & 90,879 & & 101,828 & & 278,302 & $100 \%$ & 268,503 & $100 \%$ \\
\hline International balance & & & & & -3731 & & $-11,770$ & \\
\hline Pumped storage consumption & & & & & $-11,040$ & & -5023 & \\
\hline Total demand & & & & & 263,531 & & 251,710 & \\
\hline
\end{tabular}

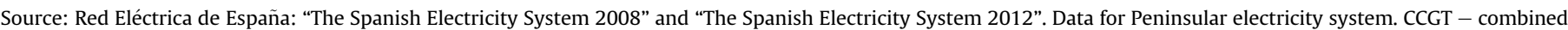
cycle gas turbine.

of the current study) is managed by OMEL (Operator responsible for the Electricity Spot Market). The wholesale electricity spot price formation in OMEL uses "market splitting" procedure to solve cross-border congestion management. A single Iberian price applies if there is no congestion in the interconnection between Spain and Portugal and distinct prices apply if there is congestion in the interconnection between the countries (Silva and Soares, 2008). Table 1 shows the evolution of the total installed capacity and production by technology from 2008 to 2012.

Considering the data presented in Table 1, produced renewable energy, particularly hydroelectric and wind energy, play a crucial role on the Spanish energy mix. Therefore, it is likely to observe an impact on electricity market prices during periods of high intensity supply from hydro and wind resources. This influence has already been presented by Gelabert et al. (2011) for the Spanish electricity market, where the authors concluded that a marginal increment of $1 \mathrm{GWh}$ of electricity from renewable sources would lead to a reduction in electricity prices of $2 € / \mathrm{MWh}$.

The present work focuses first on the entire Phase II of the EU ETS, ranging from January 2008 to December 2012. Later, this analysis will be extended to the first year of Phase III, from January to December 2013. Daily data for working days is used (weekend and national holidays are excluded because of significantly distinct demand). The electricity series from OMEL are the day-ahead prices $(€ / \mathrm{MWh}$ ) for the three load regimes: peak load, off-peak load, and base load. The peak price is the hourly average of spot prices quoted from 8:00 $\mathrm{h}$ to $20: 00 \mathrm{~h}$, while the off-peak block covers the remaining time. The base-load price is the average of the 24 hourly prices quoted during a day. The natural gas price ( $€ / \mathrm{MWh}$ gas) is the spot price from the TTF (Title Transfer Facility) trading hub. ${ }^{1}$ The coal price ( $€ /$ ton.) is the spot index API\#2 (CIF ARA $\left.{ }^{2}\right)$. The EUA price series ( $€ /$ ton.) is the spot price quoted at European Energy Exchange (EEX, Leipzig, Germany). We transformed the price variables into their natural logarithms to reduce variability, thus obtaining directly the elasticity values from the parameter estimates (Table 2).

\footnotetext{
1 TTF in Netherlands is one of the most important trading hubs in Europe; physical natural gas delivery at national trading point, the Dutch Title Transfer Facility.

2 Delivered to the Amsterdam/Rotterdam/Antwerp region.
}

As previously stated, the analysis of the relationship between electricity and production input prices (i.e., $\mathrm{CO}_{2}$ emission permits, natural gas, and coal) must be controlled by the intensity of renewable energy on the market. The selected variables to represent the quantity of electricity from hydro and wind sources are: Hydroelectric Productibility Index (Hydro) and Wind Power Productibility Index (Wind). These indexes are the quotient between the electricity produced by the hydroelectric/wind technology for a period of time and the historical average, both related to the same period (month) and to the same hydroelectric equipment. ${ }^{3}$

Climate variables (such as temperature or rainfall) may also influence the relationship between electricity and carbon prices. As shown by Engle et al. (1986) as well as by Fezzi and Bunn (2009), Fell (2010), and Blázquez et al. (2013) for the Spanish case, the relationship between electricity demand and air temperature is non-linear (a "V" shaped function) as electricity is used for both heating and cooling purposes. We therefore modeled temperature as a deviation from a threshold. We defined two climate variables: $H D D$ (heating degree days), which represents the deviations of mean temperature below the threshold of cold (increasing electricity demand is mainly for heating purposes), and CDD (cooling degree days), which represents the deviations above the threshold of heat (increasing electricity demand is mainly for cooling purposes). ${ }^{4}$ We used the thresholds proposed by Blázquez et al. (2013) for the Spanish case, considering the level of $15{ }^{\circ} \mathrm{C}$ for $H D D$ and $22^{\circ} \mathrm{C}$ for $C D D$. These variables, like produced renewable energy, are treated in the econometric model as exogenous variables.

In Fig. 1 we can observe the significant seasonality associated with the electricity prices. This effect is particularly evident in the strong price reductions verified during winters, corresponding to period of abundant electricity production from hydro and wind sources. There is also the possibility that this effect is strengthened by the growth of installed capacity, as presented in Table 1 ,

\footnotetext{
3 The quantity of electricity produced is considered per MWh of installed capacity for each period. For hydroelectricity the index is published directly by REE. For wind energy the index is computed by the authors, considering a period of 5 year for the historic mean.

${ }^{4} \mathrm{HDD}=\max \left(\mathrm{T}^{*}-\mathrm{T}_{\mathrm{t}} ; 0\right)$ and $\mathrm{CDD}=\max \left(\mathrm{T}_{\mathrm{t}}-\mathrm{T}^{* *} ; 0\right)$, with $\mathrm{T}_{\mathrm{t}}$ representing the mean daily temperature, $\mathrm{T}^{*}$ the cold threshold and $\mathrm{T}^{* *}$ heat threshold. We use the mean daily air temperature at representative weather stations weighted by population (NUTS II - Eurostat).
} 
Table 2

Summary statistics

\begin{tabular}{|c|c|c|c|c|c|c|c|c|c|c|}
\hline \multirow[b]{4}{*}{ Unit } & \multicolumn{6}{|c|}{ Endogenous Variables - Prices } & \multicolumn{4}{|c|}{ Exogenous Variables } \\
\hline & \multicolumn{3}{|c|}{ Electricity } & \multicolumn{3}{|l|}{ Inputs } & \multicolumn{2}{|c|}{ Renewables } & \multicolumn{2}{|c|}{ Temperature } \\
\hline & Base & Peak & Off-peak & Carbon & Gas & Coal & Hydro & Wind & CDD & HDD \\
\hline & $€ / \mathrm{MWh}$ & $€ / \mathrm{MWh}$ & $€ / \mathrm{MWh}$ & $€ /$ Ton. & $€ / \mathrm{MWh}$ & $€ /$ Ton. & Index & Index & ${ }^{\circ} \mathrm{C}$ & ${ }^{\circ} \mathrm{C}$ \\
\hline Mean & 48.27 & 52.47 & 44.08 & 14.23 & 20.43 & 75.93 & 0.79 & 1.01 & 0.82 & 1.90 \\
\hline Median & 48.34 & 52.19 & 44.30 & 14.17 & 22.49 & 73.85 & 0.76 & 0.99 & & \\
\hline Maximum & 82.13 & 93.67 & 72.98 & 29.33 & 37.75 & 141.91 & 1.72 & 1.52 & 7.85 & 12.55 \\
\hline Minimum & 4.62 & 3.47 & 5.78 & 5.99 & 7.00 & 42.46 & 0.16 & 0.70 & & \\
\hline Std. Dev. & 12.48 & 13.45 & 11.95 & 5.29 & 5.81 & 20.20 & 0.36 & 0.17 & 1.55 & 2.78 \\
\hline Coef. Var. & 0.26 & 0.26 & 0.27 & 0.37 & 0.28 & 0.27 & 0.46 & 0.17 & 1.88 & 1.46 \\
\hline Skewness & 0.09 & 0.26 & -0.12 & 0.65 & -0.63 & 0.69 & 0.29 & 0.55 & 1.85 & 1.37 \\
\hline Kurtosis & 0.03 & 0.22 & -0.05 & -0.03 & -0.65 & 0.64 & -0.48 & 0.23 & 2.52 & 0.88 \\
\hline
\end{tabular}

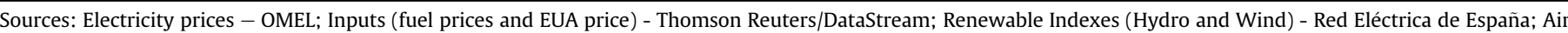
temperatures - European Climate Assessment \& Dataset (ECA\&D). Population - Eurostat.

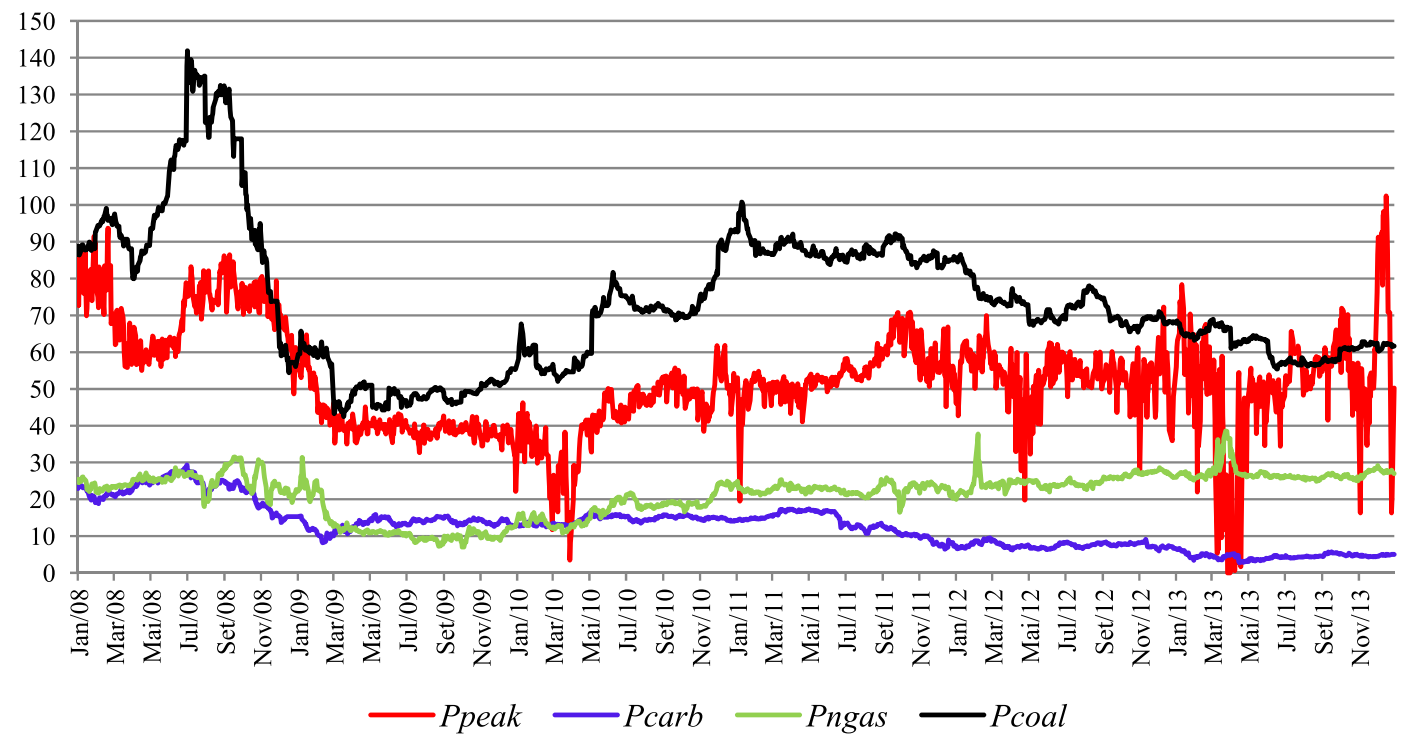

Fig. 1. Electricity, carbon and fuel prices.

$P_{\text {peak }}$ - electricity price (peak hours); $P_{\text {carb }}$ - carbon (EUA) price; Pngas - natural gas price; $P_{\text {coal }}-$ coal price.

especially in the case of wind energy. Regarding the $\mathrm{CO}_{2}$ market, the price of emission permits decreased from $30 € /$ ton in mid-2008 to a $5 € /$ ton in mid-2013. Koch et al. (2014) and Fagiani et al. (2014) present as main causes for this collapse on $\mathrm{CO}_{2}$ prices, the economic recession that followed the financial crisis of 2008 as well as the stimuli for renewable energies from public policies. Van den Bergh et al. (2013) also identify the growth of renewable energy penetration as the main cause of the $\mathrm{CO}_{2}$ price decrease, along with the fact that the amount of emission permits issued during Phase III (2013-2020) appears to be excessive relative to actual needs.

\section{Model description}

It is becoming well known that dynamic interactions may be important in the formation of electricity prices. In understanding the interaction of electricity and input prices, there are complex relationships to consider. For instance, given the marginal technologies present in the Spanish electricity system, it would appear likely that coal and natural gas prices influence electricity prices and also EUA prices, as shown by Mansanet-Bataller et al. (2007) and Alberola et al. (2008). The multivariate approach of simultaneous equations is well suited to handle with the possible endogeneity problems arising from those interactions. With this econometric technique, all price variables in the model are treated as endogenous.

Multivariate analysis has been developed using either the vector autoregressive (VAR) models or co-integrated VAR models. The cointegration concept, introduced by Engle and Granger (1987), means that individual economic variables may be non-stationary and wander through time, but a linear combination of them may converge to a stationary process. Such a process, if present, may reflect the long-run equilibrium relationship and is referred to as the cointegration equation. As noted in Engle and Granger (1987), there are strong beliefs that economic data are non-stationary, which can lead to spurious regression results. Removing the nonstationarity by differencing the variables imposes the risk of losing relevant information about long-term relationships. Alternatively, the VAR can be improved to handle cointegrated variables in what is commonly referred as a VECM. This latter alternative, if possible, has the advantage of allowing the simultaneous analysis of the long-run interactions and the short-term adjustments to the equilibrium relationship.

The specification in this study follows Johansen (1991). Assuming the existence of cointegration, the data generating process $P_{t}$ can be appropriately modeled as a VECM with $k-1$ lags (which is derived from a levels VAR of order $k$ ). Consider a VAR of 
order $k$ with a deterministic part given by $\mu_{t}$. One can write the $p$ variate process as. $P_{t}=\mu_{t}+A_{1} P_{t-1}+A_{2} P_{t-2}+\cdots+A_{k} P_{t-k}+\varepsilon_{t}$.

Taking the variables in first differences, with $\Delta$ as the difference operator $\left(\Delta P=P_{t}-P_{t-1}\right)$, than $P_{t-i} \equiv P_{t-1}-\left(\Delta P_{t-1}+\Delta P_{t-2}+\ldots\right.$ $\left.+\Delta P_{t-i+1}\right)$ and one can re-write the process as:

$\Delta P_{t}=\Pi P_{t-1}+\sum_{i=1}^{k-1} \Gamma_{i} \Delta P_{t-i}+\mu_{t}+\varepsilon_{t}$

Where $\Pi=\sum_{i=1}^{k} A_{i}-I \quad \Gamma_{i}=-\sum_{j=i+1}^{k} A_{j} \quad \varepsilon_{t} \sim \operatorname{Niid}(0, \Sigma)$

In Eq. (1) $P_{t}$ represents a vector of $p$ non-stationary endogenous variables and the matrix $\Pi$ contains information about the long-run relationship among endogenous variables and can be decomposed as $\Pi=\alpha \beta^{\prime}$, whereas $\beta$ represents the cointegration vectors and $\alpha$ the matrix with the estimations on the speed of adjustment to the equilibrium. The matrix $\Pi$ is called an error correction term, which compensates for the long-run information lost through differencing. The rank of matrix $\Pi(r)$ determines the long-run relationship. If the rank of the matrix $\Pi$ is zero $(r=0)$, there is no longrun relationship and the model above is equal to a VAR in differences. If the matrix $\Pi$ has the full rank $(r=p)$, then it is invertible, meaning that the processes $P_{t}$ is stationary $\mathrm{I}(0)$ and a normal VAR in levels can be used. The cointegration relationship occurs when the order of the matrix is between 0 and $p(0<r<p)$ and there are $(p \times r)$ matrices $\alpha$ and $\beta$ such that the equation $\Pi=\alpha \beta^{\prime}$ holds. In this case, $P_{t}$ is integrated of first order I(1) but the linear combination $X_{t}=\beta^{\prime} P_{t}$ is I $(0)$. If, for example, $r=1$ and the first element of $\beta$ was $\beta=-1$, then one could write the linear combination as $X_{t}=-P_{1, t}+\beta_{2} P_{2, t}+\ldots+\beta_{p} P_{p, t}$, which is equivalent to saying that long-run equilibrium relationship among variables of vector $P_{t}$ is expressed as $P_{1, t}=\beta_{2} P_{2, t}+\ldots+\beta_{p} P_{p, t}-X_{t}$. This long-run relationship may not hold all the time, however the deviation $X_{t}$ is stationary I(0). In this case, Eq. (1) can be written as:

$\Delta P_{t}=\alpha \beta P_{t-1}^{\prime}+\sum_{i=1}^{k-1} \Gamma_{i} \Delta P_{t-1}+\mu_{t}+\varepsilon_{t}$

This approach was extended by Harbo et al. (1998) and Pesaran et al. (2000) to include exogenous variables in the model. This is particularly useful in our case because it allows an adequate treatment of the renewable energy and temperature variables.

We formulate a general VECM specification as:

$\Delta P_{t}=\alpha \beta P_{t-1}^{\prime}+\sum_{i=1}^{k-1} \Gamma_{i} \Delta P_{t-1}+\theta R_{t}^{\prime}+\Phi T_{t}+\mu_{t}+S d_{t}+\varepsilon_{t}$

- Where $P_{t}$ is a $(4 \times 1)$ vector of prices (endogenous variables) measured at time $t: P_{\mathrm{t}}=\left[P_{t}^{\text {peak }}, P_{t}^{\text {carb }}, P_{t}^{\text {gas }}, P_{t}^{\text {coal }}\right]-P_{t}^{\text {peak }}$ is the natural logarithm of electricity price, $P_{t}^{c a r b}$ is the natural logarithm of $\mathrm{CO}_{2}$ emission allowances price, $P_{t}^{\text {gas }}$ is the natural logarithm of natural gas price and $P_{t}^{\text {coal }}$ is the natural logarithm of coal price. Terms $\alpha$ and $\beta$ are a $(4 \times r)^{5}$ matrix, whereas $\beta$ and $\alpha$ represent, respectively, the cointegrating vectors and the matrix with the estimations on the speed of adjustments to the equilibrium.

\footnotetext{
${ }^{5}$ Where $r$ is the number of cointegrating vectors.
}

- Where $\Gamma_{\mathrm{i}}$ is a $(4 \times 4)$ matrix with the estimations of short-run parameters relating price changes lagged $i$ periods.

- Where $\theta$ is a $(2 \times r)$ matrix of coefficients associated with the $(2 \times 1)$ vector $R_{t}$ that represents the exogenous renewables variables ${ }^{6}: R_{t}=\left[\operatorname{Ind}_{t}^{\text {hydro }}, \operatorname{Ind}_{t}^{\text {wind }}\right]-\operatorname{Ind}_{t}^{\text {hydro }}$ is the Hydroelectric Producibility Index and Indwind represents the Wind Power Producibility Index.

- Where $\Phi$ is a $(4 \times 2)$ matrix of coefficients associated with the $(2 \times 1)$ vector $T_{t}$ that represents the exogenous temperatures variables: $T_{t}=\left[C D D_{t}, H D D_{t}\right]$ with $H D D$ and $C D D$ as defined previously.

- Where $\mu_{t}$ is a $(r \times 1)$ vector of constant ${ }^{7}$ and $\varepsilon_{t}$ is a $(4 \times 1)$ vector of innovations.

- Where $d_{t}$ is a deterministic component containing centered seasonal dummy variables to capture the weakly and monthly seasonality.

In this study we test the hypothesis of a long-run relationship (or cointegration) between the price of the electricity, the price of carbon, and the prices of fuels (natural gas and coal), taking into account the amount of renewable electricity present in the market and the effect of the weather on electricity demand. According to our theory, as supported by the literature, we expect a positive relationship between the electricity price and the input prices (carbon and fuels), a negative sign for the coefficients representing renewable energy, and a positive sign for the coefficients representing temperature. Because the electricity price response to changes in $\mathrm{CO}_{2}$ price may not be constant across time, we test our model for the three different load regimes (peak load, off-peak load, and base load).

\section{Empirical results}

\subsection{Unit root and cointegration tests}

We started our estimation procedure by testing the nonstationarity for all price series. The tests were conducted using the natural logarithms of the price series (electricity, EUA, natural gas, and coal). As shown in Table 3, all series fail to reject the null of a unit root for all specifications tested, according both the Augmented Dickey-Fuller Test (ADF test) and the Unit Root test with Breaks, which accounts for the possibility of level shift. When testing for stationarity, the Kwiatkowski, Phillips, Schmidt and Shin Test (KPSS test), all series reject the null at a $1 \%$ significance level. On the contrary, we have evidence that the differenced series are stationary (ADF test and KPSS test). These results provide evidence for the hypotheses that all prices are non-stationary in levels, but have stationary first differences.

The first step in the modeling procedure is to determine the lag relationship among the price series in the levels VAR. The AIC (Akaike Info Criterion), SIC (Schwarz Info Criterion), and HQC (Hannan and Quinn Criterion) loss metrics suggest the appropriate VAR lag length is two ${ }^{8}(k=2)$, indicate that the inclusion of exogenous variables (both the generation mix variables and weather variables) improves the fit of the VAR to the data, and suggest not including lags in the exogenous variables.

The tests of cointegration were implemented with the technique based on the reduced rank regression introduced by Johansen

\footnotetext{
6 The renewables variables are inside (restricted) of the cointegration relations.

${ }^{7}$ Actually $\Pi=\alpha \beta^{\prime}$ may be of order $(4 \times 5)$ or $(4 \times 4)$ depending on whether the constant is inside or outside (restricted or unrestricted) of the cointegration space.

${ }^{8}$ As the VAR is specified in first differences, the number of lags lag in the VECM should be one $(k-1)$.
} 
Table 3

Unit root tests.

\begin{tabular}{|c|c|c|c|c|c|c|c|c|c|c|c|c|c|}
\hline \multicolumn{6}{|c|}{ ADF tests } & \multicolumn{4}{|c|}{ KPSS tests } & \multicolumn{4}{|c|}{ Unit root tests with breaks } \\
\hline \multicolumn{10}{|c|}{ Natural Logarithm of Prices - Levels } & \multicolumn{4}{|c|}{ Natural Log. of Prices - Levels } \\
\hline & Lag & \multicolumn{2}{|c|}{ Constant } & \multicolumn{2}{|c|}{ Const\&Trend } & \multirow[t]{2}{*}{ Lag } & \multirow{2}{*}{\multicolumn{2}{|c|}{$\begin{array}{l}\text { Constant } \\
\text { Stat. }\end{array}$}} & \multirow{2}{*}{$\begin{array}{l}\text { Const\&Trend } \\
\text { Stat. }\end{array}$} & \multicolumn{2}{|l|}{ Lag } & \multicolumn{2}{|c|}{ Constant } \\
\hline & & Stat. & p-value & Stat. & p-value & & & & & & & Stat. & \\
\hline Ppeak & 13 & -2.58 & 0.10 & -2.53 & 0.31 & 8 & $1.96^{* * *}$ & & $1.93^{* * *}$ & Ppeak & 13 & -1.36 & - \\
\hline Pcarb & 2 & -1.09 & 0.72 & -2.19 & 0.49 & 8 & $9.29^{* * *}$ & & $1.12^{* * *}$ & Pcarb & 2 & -0.61 & - \\
\hline Pngas & 0 & -2.14 & 0.23 & -2.41 & 0.37 & 8 & $3.29 * * *$ & & $2.02^{* * *}$ & Pngas & 0 & -1.47 & - \\
\hline Pcoal & 0 & -1.36 & 0.60 & -1.35 & 0.87 & 8 & $1.54^{* * *}$ & & $1.58^{* * *}$ & Pcoal & 0 & -1.35 & - \\
\hline \multicolumn{14}{|c|}{ Natural Logarithm of Prices - First Diferrences } \\
\hline & \multirow[t]{2}{*}{ Lag } & \multicolumn{2}{|c|}{ Constant } & \multicolumn{2}{|c|}{ No Constant } & Lag & \multirow{2}{*}{\multicolumn{2}{|c|}{$\begin{array}{l}\text { Constant } \\
\text { Stat. }\end{array}$}} & & \multirow[t]{2}{*}{ Lag } & & \multirow{2}{*}{\multicolumn{2}{|c|}{$\begin{array}{l}\text { Const.\&Trend. } \\
\text { Stat. }\end{array}$}} \\
\hline & & Stat. & p-value & Stat. & p-value & & & & & & & & \\
\hline$\Delta P^{\text {peak }}$ & 12 & -14.7 & 0.00 & -14.7 & 0.00 & 8 & 0.03 & - & & Ppeak & 13 & -1.65 & - \\
\hline$\Delta P^{c a r b}$ & 1 & -26.0 & 0.00 & -26.0 & 0.00 & 8 & 0.06 & - & & Pcarb & 2 & -1.80 & - \\
\hline$\Delta P^{\text {ngas }}$ & 0 & -36.8 & 0.00 & -36.9 & 0.00 & 8 & 0.11 & - & & Pngas & 0 & -1.91 & - \\
\hline$\Delta P^{\text {coal }}$ & 0 & -33.7 & 0.00 & -33.7 & 0.00 & 8 & 0.16 & - & & Pcoal & 0 & -1.34 & - \\
\hline
\end{tabular}

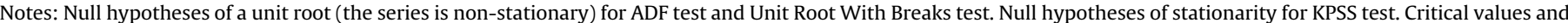

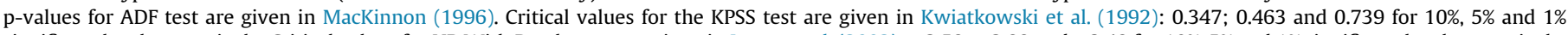

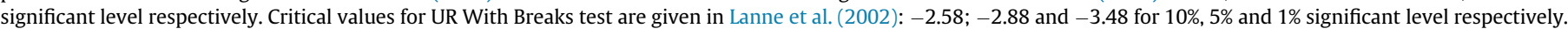

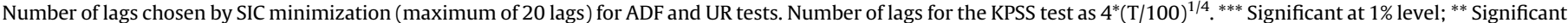
at $5 \%$ level; ${ }^{*}$ Significant at $10 \%$ level.

Table 4

Cointegration tests.

\begin{tabular}{|c|c|c|c|c|c|c|c|c|}
\hline \multicolumn{3}{|c|}{$H_{O}:$} & \multicolumn{3}{|c|}{ Trace test } & \multicolumn{3}{|c|}{$\lambda_{\max }-\max$ Eigen Value test } \\
\hline$r=$ & $\begin{array}{l}=p- \\
r=\end{array}$ & $\begin{array}{l}\text { Eigen } \\
\text { values }\end{array}$ & Statistics & $\begin{array}{l}\text { Critical } \\
\text { values }\end{array}$ & $\begin{array}{l}\mathrm{p}- \\
\text { values }\end{array}$ & Statistics & $\begin{array}{l}\text { Critical } \\
\text { values }\end{array}$ & $\begin{array}{l}\mathrm{p}- \\
\text { values }\end{array}$ \\
\hline 0 & 4 & 0.0963 & 174.49 & 91.59 & 0.00 & 127.65 & 41.57 & 0.00 \\
\hline 1 & 3 & 0.0250 & 46.84 & 64.33 & 0.52 & 31.88 & 35.09 & 0.11 \\
\hline 2 & 2 & 0.0092 & 14.96 & 40.85 & 0.98 & 11.59 & 28.31 & 0.93 \\
\hline 3 & 1 & 0.0027 & 3.38 & 20.84 & 1.00 & 3.38 & 20.84 & 0.99 \\
\hline
\end{tabular}

Notes: $5 \%$ significant level for critical values. p-values calculated using the software in Mackinnon et al. (1999). Model with restricted constant, two lags in endogenous variables and 4 exogenous variables. $p$ refers to the number of endogenous variables. $r$ refers to the number of cointegrated vectors.

(1991). Since the VAR model contains exogenous variables, the Osterwald-Lenum (1992) and Johansen (1995) asymptotic critical values are no longer valid; we therefore used the asymptotic critical values provided by Mackinnon et al. (1999). The decision of whether the constant is within or outside of the cointegration space was based on the three metrics, and the results recommend restricting the intercept to lie within the cointegration space.

The results for both Trace Test and $\lambda_{\max }$ Statistics, presented in Table 4, clearly indicate the existence of one cointegrated vector $(r=1)$. Thus, we proceed under the result of a single long-run relationship among the variables.

\subsection{Estimation results for phase II of EU ETS (2008/2012)}

With the cointegration rank and optimum number of lags determined, the parameters of model can be estimated. The results reported in Table 5 for the cointegrated vector $\beta$, which is normalized on $P_{t-1}^{\text {peak }}$, show that all estimated parameters have the correct $\operatorname{sign}^{9}$ and they are all significant (at a 5\% significance level for coal price and at $1 \%$ significance for all other variables) according to both the t-test and the LR test (Likelihood Ratio Test) as shown by Johansen $(1995)^{10}$. Since the coefficients can be interpreted as price elasticities, a carbon price rise of $1 \%$ would, in

\footnotetext{
${ }^{9}$ All the variables (dependent and explanatory) are on the same side of the cointegration equation, resulting in the signs presented by the coefficients to be inverse to the positive or negative effect that the explanatory variables have on the dependent variable (price of electricity).

${ }^{10}$ The results for the LR test are given in Table 6 (Exclusion Tests).
}

Table 5

VECM parameter estimates.

\begin{tabular}{|c|c|c|c|c|}
\hline \multicolumn{5}{|c|}{ Cointegration Relationship } \\
\hline \multicolumn{5}{|c|}{ Endogenous Variables } \\
\hline & $P_{t}^{\text {peak }}$ & $P_{t}^{c a r b}$ & $P_{t}^{\text {ngas }}$ & $P_{t}^{\text {coal }}$ \\
\hline & 1.00 & $-0.24^{* * *}(0.04)$ & $-0.39 * * *(0.07)$ & $-0.19^{* *}(0.09)$ \\
\hline \multicolumn{5}{|c|}{ Exogenous Variables + Deterministic Terms } \\
\hline & Ind hydro & Ind ${ }^{\text {wind }}$ & Const. & \\
\hline & $0.30^{* * *}(0.03)$ & $0.28^{* * *}(0.07)$ & $-1.80^{* * *}(0.21)$ & \\
\hline \multicolumn{5}{|c|}{ Short Run Dynamics } \\
\hline & $\Delta P_{t}^{\text {peak }}$ & $\Delta P_{t}^{c a r b}$ & $\Delta P_{t}^{\text {ngas }}$ & $\Delta P_{t}^{\text {coal }}$ \\
\hline$E C_{t-1}$ & $-0.28^{* * *}$ & - & - & - \\
\hline$\Delta P_{t-1}^{\text {peak }}$ & $-0.25^{* * *}$ & $0.01^{* *}$ & - & - \\
\hline$\Delta P_{t-1}^{c-1}$ & - & $0.05^{*}$ & $0.11^{* *}$ & $0.09^{* * *}$ \\
\hline$\Delta P_{t-1}^{n g a s}$ & - & - & $-0.05^{*}$ & - \\
\hline$\Delta P_{t-1}^{c-1}$ & - & $-0.12^{* * *}$ & - & $0.05^{*}$ \\
\hline \multicolumn{5}{|c|}{ Exogenous Variables + Seasonal Dummies } \\
\hline$C D D$ & $0.005^{* * *}$ & - & - & - \\
\hline$H D D$ & $0.005^{* * *}$ & - & - & - \\
\hline Day of week & $* * *$ & - & - & - \\
\hline Month of year & $* * *$ & - & $* *$ & $*$ \\
\hline
\end{tabular}

Notes: $E C_{t-1}$ refers to the adjustment coefficients $(\alpha)$. We only present the significant coefficients. Standard errors in parentheses. t-statistics significance test: ${ }^{* * *}$ Significant at $1 \%$ level; ${ }^{* *}$ Significant at $5 \%$ level; * Significant at $10 \%$ level.

equilibrium, be associated with an electricity price rise of $0.24 \%$. In the same way, a natural gas (coal) price rise of $1 \%$ would be associated with an electricity price rise of $0.39 \%(0.19 \%)$.

This pass-through rate of the $\mathrm{CO}_{2}$ price into electricity price of $24 \%$ compares with the estimate of $93 \%$ in Honkatukia et al. (2006)

Table 6

Exclusion and long-run or weak exogeneity tests.

\begin{tabular}{lccccc}
\hline & \multicolumn{2}{l}{ Exclusion Test } & & \multicolumn{2}{l}{ Exogeneity Test } \\
\cline { 2 - 3 } \cline { 5 - 6 } & LR stat. & p-value & & LR stat. & p-value \\
\hline$P^{\text {peak }}$ & 129.1 & 0.00 & & 128.7 & 0.00 \\
$P^{\text {carb }}$ & 28.6 & 0.00 & 0.2 & 0.65 \\
$P^{\text {ngas }}$ & 23.0 & 0.00 & 0.2 & 0.63 \\
$P^{\text {coal }}$ & 3.3 & 0.07 & & 1.8 & 0.18 \\
Ind $^{\text {hydro }}$ & 45.1 & 0.00 & & \\
Ind $^{\text {wind }}$ & 16.7 & 0.00 & & \\
const $^{n}$ & 47.1 & 0.00 & & & \\
\hline
\end{tabular}

Notes: LR refers to Likelihood Ratio Test statistics. 
Table 7

Diagnostic tests on residuals.

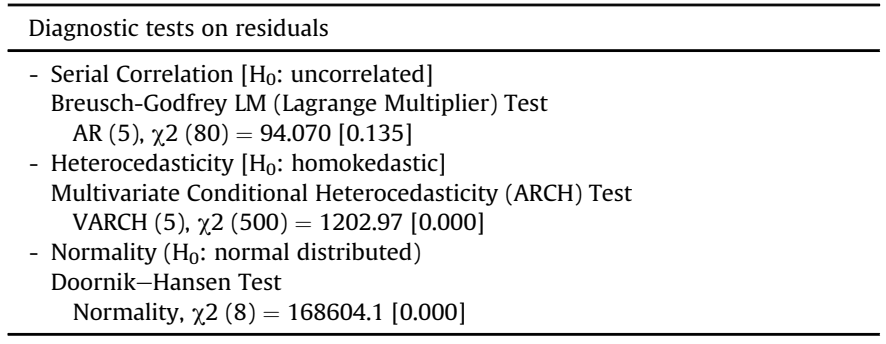

Notes: p-values in parentheses.

Table 8

Residuals correlation matrix.

\begin{tabular}{lllll}
\hline$\Delta P^{\text {peak }}$ & 1 & 0.015 & 0.009 & -0.018 \\
$\Delta P^{\text {carb }}$ & - & 1 & 0.097 & -0.045 \\
$\Delta P^{\text {gas }}$ & - & - & 1 & 0.060 \\
$\Delta P^{\text {coal }}$ & - & - & - & 1 \\
\hline
\end{tabular}

of the dummy variables that the model is correctly adjusted to seasonality, for both the day of the week and month of the year.

A weak long-run exogeneity test is performed (Juselius, 2006) for the null hypothesis that each of the series does not respond to the innovations or shocks in the cointegration space, (i.e., the series is unresponsive to deviations from the long-run relationships). This test is performed on $\alpha$. According to the results reported in Table 6, at $1 \%$ significance, only the electricity price series rejects the null, meaning that the long-run relationships in the data are important only for the electricity price. These results are as expected since carbon, natural gas, and coal are globally traded commodities and thus may be driven more by forces outside the Spanish energy market. An exclusion test also is performed (Juselius, 2006) for the null hypothesis that a particular series is not in the cointegration space. This test is performed on $\beta$. As we can see, with the exception of coal price, all series reject the null at $1 \%$ significance, meaning that all coefficients are strongly significant. The presence of the coal price in the long-run relationship requires acceptance of a $10 \%$ significance level. Hence, there is strong evidence that all of the

Table 9

Results for different regimes load.

\begin{tabular}{|c|c|c|c|c|c|c|}
\hline \multicolumn{7}{|c|}{ Price of electricity: Peak load } \\
\hline$P_{t}^{\text {peak }}$ & $P_{t}^{c a r b}$ & $P_{t}^{g a s}$ & $P_{t}^{\text {coal }}$ & Ind ${ }^{\text {hydro }}$ & Ind ${ }^{\text {wind }}$ & Const. \\
\hline $\begin{array}{l}1.000^{* * *}(0.00) \\
E C_{t-1}=-0.28^{* * *}\end{array}$ & $-0.241^{* * *}(0.04)$ & $-0.391^{* * *}(0.07)$ & $-0.186 *(0.09)$ & $0.297^{* * *}(0.03)$ & $0.278^{* * *}(0.07)$ & $-1.803^{* * *}(0.21)$ \\
\hline \multicolumn{7}{|c|}{ Price of Electricity: off-peak load } \\
\hline$P_{t}^{\text {off-peak }}$ & $P_{t}^{c a r b}$ & $P_{t}^{g a s}$ & $P_{t}^{\text {coal }}$ & Ind $^{\text {hydro }}$ & Ind ${ }^{\text {wind }}$ & Const. \\
\hline $\begin{array}{l}1.000^{* * *}(0.00) \\
E C_{t-1}=-0.26^{* * *}\end{array}$ & $-0.245^{* * *}(0.06)$ & $-0.394^{* * *}(0.10)$ & $-0.235-(0.13)$ & $0.352^{* * *}(0.05)$ & $0.265^{* * *}(0.09)$ & $-1.378^{* * *}(0.30)$ \\
\hline \multicolumn{7}{|c|}{ Price of Electricity: base load } \\
\hline$\overline{P_{t}^{\text {base }}}$ & $P_{t}^{c a r b}$ & $P_{t}^{g a s}$ & $P_{t}^{\text {coal }}$ & Ind ${ }^{\text {hydro }}$ & Ind ${ }^{\text {wind }}$ & Const. \\
\hline $\begin{array}{l}1.000^{* * *}(0.00) \\
E C_{t-1}=-0.28^{* * *}\end{array}$ & $-0.254^{* * *}(0.04)$ & $-0.409^{* * *}(0.07)$ & $-0.172 *(0.09)$ & $0.322^{* * *}(0.03)$ & $0.245^{* * *}(0.07)$ & $-1.682^{* * *}(0.21)$ \\
\hline
\end{tabular}

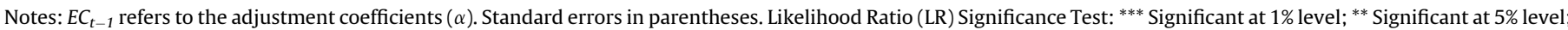

* Significant at $10 \%$ level.

for the NordPool market, 32\% in Fezzi and Bunn (2009) for the UK market, 11\%-13\% in Fell (2010) for the NordPool market, 36\% in Thoenes (2011) for the German market, 70\% in Aatola et al. (2013) for the French market, and 51\% in Freitas and Silva (2013) for the Portuguese market. In addition, the results we found are below the simulations for the Spanish market of 60\%-63\% in Sijm et al. (2008) and $60 \%-100 \%$ in Lise et al. (2010). Moreover, the sign and statistical significance of the associated coefficients for the renewables indexes are as expected (Ind ${ }^{\text {hydro }}$ e Ind ${ }^{\text {wind }}$ ), reflecting the negative impact of the quantity of renewable energy on electricity prices and therefore confirming the results presented by Gelabert et al. (2011).

Analyzing the short-run dynamics of the model, especially for the equation of interest $\left(\Delta P_{t}^{\text {peak }}\right)$, we can see that the error correction term $\left(E C_{t-1}\right)$ is strongly significant (1\% level) and negative, meaning that the electricity price is adjusting to a long-run equilibrium, with a speed of adjustment of 0.28 (i.e., $28 \%$ of the disequilibrium in the long-run price is correct in one period). Considering the short-run parameters in the VAR, only the lagged electricity price is significant, suggesting that the price of electricity is essentially exogenous in the short run. There is also strong evidence that the weather variables are important for electricity price changes in the short run, having a positive impact when the demand of electricity reflects either heating (HDD) or cooling (CDD) purposes. It is also possible to verify from the statistical significance price series (carbon, gas, and coal prices) and the amount of renewable energy, both hydroelectric and wind power, are important to define the equilibrium vector; that is, all are essential to define the level to which electricity price is attracted over time. ${ }^{11}$

Although residual analysis (Table 7) shows evidence of autoregressive conditional heterocedasticity $(\mathrm{ARCH})$ and non-normality, this is not likely to be a major problem in our cointegration analysis since Gonzalo (1994) showed that the properties of asymptotically optimal inferences present on maximum likelihood estimators hold in finite samples even without the normality assumption. Observing the residuals correlation matrix (Table 8) we can see that the correlations among all equations are very low.

In Table 9 we report the results for the strategy implemented to consider significant differences in the pass-through rate of $\mathrm{CO}_{2}$ price into electricity price across time. We estimated three alternative models defined according to electricity load regimes (peak load, off-peak load, and base load). As we can see, the coefficient associated with the carbon price for the three models is not significantly different, demonstrating that the impact of carbon on

\footnotetext{
11 An exclusion test is also performed on the constant term, which results in a rejection of the null hypothesis. This agrees with the inclusion of the constant parameter in the cointegration space.
} 
Table 10

Results for different periods of phase II and phase III of EU ETS.

\begin{tabular}{|c|c|c|c|c|c|}
\hline \multicolumn{6}{|c|}{ Period: jan./2008_jun./2011 (part of phase II of EU ETS) } \\
\hline$P_{t}^{c a r b}$ & $P_{t}^{g a s}$ & $P_{t}^{\text {coal }}$ & Ind hydro $^{\text {hy }}$ & Ind wind $^{\text {win }}$ & Const. \\
\hline $\begin{array}{l}1.000^{* * *}(0.00) \quad-0.365^{* * *}(0.11) \\
E C_{t-1}=-0.241^{* * *}(0.02)\end{array}$ & $-0.392^{* * *}(0.09)$ & $-0.130-(0.13)$ & $0.351^{* * *}(0.04)$ & $0.288^{* * *}(0.09)$ & $-1.655^{* * *}(0.26)$ \\
\hline \multicolumn{6}{|c|}{ Period: jan./2008_dec./2012 (all Phase III of EU ETS) } \\
\hline$P_{t}^{c a r b}$ & $P_{t}^{g a s}$ & $P_{t}^{\text {coal }}$ & Ind hydro $^{\text {hy }}$ & Ind Iind $^{\text {win }}$ & Const. \\
\hline $\begin{array}{l}1.000^{* * *}(0.00) \quad-0.254^{* * *}(0.04) \\
E C_{t-1}=-0.280^{* * *}(0.02)\end{array}$ & $-0.409^{* * *}(0.07)$ & $-0.172^{*}(0.09)$ & $0.322^{* * *}(0.03)$ & $0.245^{* * *}(0.07)$ & $-1.682^{* * *}(0.21)$ \\
\hline \multicolumn{6}{|c|}{ Period: jan./2008_dec./2013 (all Phase II + part of Phase III of EU ETS) } \\
\hline$P_{t}^{\text {base }}$ & $P_{t}^{g a s}$ & $P_{t}^{\text {coal }}$ & Ind ${ }^{\text {hydro }}$ & Ind $^{\text {wind }}$ & Const. \\
\hline $\begin{array}{l}1.000^{* * *}(0.00) \quad-0.187^{* *}(0.08) \\
E C_{t-1}=-0.304^{* * *}(0.02)\end{array}$ & $-0.466^{* * *}(0.14)$ & $-0.076-(0.20)$ & $0.392^{* * *}(0.06)$ & $0.210-(0.14)$ & $-2.126^{* * *}(0.46)$ \\
\hline
\end{tabular}

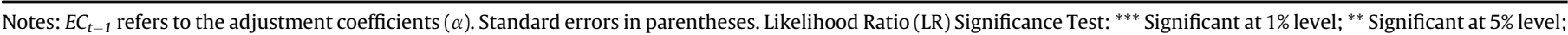
* Significant at $10 \%$ level.

electricity prices is roughly the same through all periods of the day. Only the coefficients associated with the coal price and hydroelectric index present considerable differences for the peak-hour and off-peak-hour periods. The sensitivity of the electricity price to these variables is higher in periods of lower demand, which is consistent with the fact that these technologies have lower marginal costs.

\subsection{Estimation results for phase II and phase III of EU ETS (2008/ 2013)}

Extending the analysis to Phase III of EU ETS will be important first, to understand if changes in the sector rules associated with the allocation of emission permits affect the influence $\mathrm{CO}_{2}$ on the price of electricity ${ }^{12}$ and second, to understand if the trend of falling $\mathrm{CO}_{2}$ prices affects the sensitivity of electricity prices to the cost of $\mathrm{CO}_{2}$ emissions. For this analysis, three periods were considered: a sub-period of Phase II, representing a period when the $\mathrm{CO}_{2}$ price remained consistently above the $15 € /$ ton level (January, 2008 to June, 2011); a period corresponding to the complete Phase II and whose results were previously analyzed (January, 2008 to December, 2012); and a period that included the first year of Phase III implementation (January, 2008 to December, 2013).

As presented in Table 10, the sensitivity of the electricity price to the $\mathrm{CO}_{2}$ price has diminished over time. Throughout Phase II, the price elasticity of electricity relative to the price of $\mathrm{CO}_{2}$ shifted from 0.37 to 0.25 , when the $\mathrm{CO}_{2}$ reached values below the $10 € /$ ton level and when, including the first year of Phase III, the elasticity fell to 0.19. It is important to highlight that the coefficient associated with the $\mathrm{CO}_{2}$ price for the period including Phase III is significant only at the $5 \%$ level. It can be concluded that a very low price for $\mathrm{CO}_{2}$ over extended periods of time may result in lower electricity prices that inhibit the incentives for electricity producers to invest in emissions reduction or electricity consumers to invest in end-use efficiency.

\section{Conclusion and policy implications}

We analyzed the impact of $\mathrm{CO}_{2}$ emission allowance prices on the Spanish electricity market using a cointegrated vector error correction model (VECM). This econometric approach encompasses

\footnotetext{
12 During Phase III of the EU ETS, the electric energy production sector stopped receiving emission permits at no cost (grandfathering), shifting instead to an acquisition through auction system (auctioning).
}

long-run equilibrium relations and short-run effects in the dynamic interactions between electricity price and input prices (carbon, natural gas, and coal). The effect of the input prices in electricity price was controlled through a set of exogenous variables affecting the demand for electricity (i.e., weather variables) and the amount of renewable energy resources (hydroelectric and wind power) present in the market. The model was estimated using daily data, first for a period corresponding to whole Phase II of the EU ETS (2008-2012) and then including the first year of Phase III (2008-2013).

Taking into account the fuel prices (natural gas and coal) and produced renewable energy, we demonstrate that carbon price plays an important role in formulating the long-run equilibrium price of electricity. For the period corresponding to the Phase II, when the emissions allowances were allocated to power producers for free, we estimated an electricity price elasticity of 0.24 , meaning that a $1 \%$ shock in carbon price translates to a $0.24 \%$ shock in electricity price in the long-run.

These empirical results are in line with studies concerning other European electricity markets, supporting the hypothesis that power producers during the second phase of EU ETS have passed the cost of freely allocated emission allowances through to electricity prices. It is possible to conclude that power producers' competitiveness would not have been affected if they had paid for the emissions allowances. Although a more definitive conclusion should account for the price elasticity of demand, which could be an interesting topic for future research, these results support changing the allocation rules for emissions allowances for the electricity sector from grandfathering to auctioning, as implemented by the European Commission for the Phase III of the EU ETS started at January 2013. However, estimating the model for different time lengths enables us to conclude that the sensitivity of electricity prices to the price of carbon emissions is also lower at lower carbon prices.

This study may be the first to provide empirical evidence of the impact of carbon price on electricity price during Phase III of EU ETS implementation. Our findings clearly make the case that the collapse of the $\mathrm{CO}_{2}$ price weakens the link between the carbon market and the electricity market, consequently putting at risk the policy goals associated with carbon pricing. At low carbon prices, the incentives for electricity producers to reduce their emissions (through less carbon intensive production technologies), and the stimuli for consumers to cut their long-term consumption (through more end-use efficiency) will dissipate.

Various studies have demonstrated that the decrease in the 
carbon price is evident of the excess of emission permits held by economic agents (approximately 2.1 billion permits) associated with a decline in electricity demand (driven by the decrease in economic activity) as well as by the increase in the sector's use of renewable resources (Van den Bergh et al., 2013) and Koch et al., 2014). The findings from this research confirm the risk of carbon lock-in that the EU ETS faces (i.e., the domination of fossil-fuelbased technologies despite the greater dynamic efficiency of carbon-free alternatives). Our findings also support the need for action from regulatory policies that prevent extended period of reduced carbon prices. An example of this type of action was proposed by the European Commission, and approved by the European Parliament, in December 2013, delayed the emission permits auction foreseen for Phase III (a back-loading decision). Nonetheless, to ensure the efficacy of the system for delivering environmental goals, long-term structural policies are necessary.

\section{Acknowledgments}

The authors acknowledge the freely provided data on weather: Klein Tank, A.M.G. and Coauthors, 2002. Daily dataset of 20thcentury surface air temperature and precipitation series for the European Climate Assessment Int. J. of Climatol., 22, 1441-1453. The second author would like to acknowledge that this work has been partially supported by FCT under project grant PEst-C/EEI/UI0308/ 2011 and the Energy for Sustainability Initiative of the University of Coimbra and supported by the R\&D Project EMSURE (Energy and Mobility for Sustainable Regions) - CENTRO 070224 FEDER 002004. We further acknowledge the anonymous reviewer's inputs that contributed to the improvement of the final manuscript.

\section{References}

Aatola, P., Ollikainen, M., Toppinen, A., 2013. Impact of the carbon price on the integrating European electricity market. Energy Policy 61, 1236-1251.

Alberola, E., Chevallier, J., Chèze, B., 2008. Price drivers and structural breaks in european carbon Prices: 2005-2007. Energy Policy 36 (2), 787-797.

Blázquez, L., Boogen, N., Filippini, M., 2013. Residential electricity demand in Spain: new empirical evidence using aggregate data. Energy Econ. 36, 648-657.

Boersen, A., Scholtens, B., 2014. The relationship between European electricity markets and emission allowance futures prices in phase II of the EU (European Union) emission trading scheme. Energy 74, 585-594.

Bonacina, M., Gullì, F., 2007. Electricity pricing under "carbon emissions trading": a dominant firm with competitive fringe model. Energy Policy 35 (8), 4200-4220.

Chemarin, S., Heinen, A., Strobl, E., 2008. Electricity, Carbon and Weather in France: Where Do We Stand? Ecole Polytechnique, Centre National de la Recherche Scientifique, France. Cahier No 2008-04.

Cotton, D., Mello, L., 2014. Econometric analysis of Australian emissions markets and electricity prices. Energy Policy 74, 475-485.

Engle, R., Granger, C., Rice, J., Weiss, A., 1986. Semiparametric estimates of the relation between weather and electricity sales. J. Am. Stat. Assoc. 81 (394), 310-320.

Engle, R., Granger, C., 1987. Co-Integration and error correction: representation, estimation, and testing. Econometrica 55 (2), 251-276.

Fagiani, R., Richstein, J., Hakvoort, R., Vries, L., 2014. The dynamic impact of carbon reduction and renewable support policies on the electricity sector. Util. Policy $28,28-41$.

Fell, H., 2010. EU-ets and nordic electricity: a CVAR analysis. Energy J. 31 (2), 1-25.

Ferkingstad, E., Løland, A., Wilhelmsen, M., 2011. Causal modeling and inference for electricity markets. Energy Econ. 33 (3), 404-412.

Fezzi, C., Bunn, D., 2009. Structural interactions of european carbon trading and energy prices. J. Energy Mark. 2 (4), 53-69.

Freitas, C., Silva, P., 2012. Phase II $\mathrm{CO}_{2}$ cost pass-through in MIBEL: a cointegrated VECM approach. In: 5th Atlantic Workshop on Energy and Environmental
Economics.Spain.

Freitas, C., Silva, P., 2013. Evaluation of dynamic pass-through of carbon prices into electricity prices - a cointegrated VECM analysis. Int. J. Public Policy 9 (1-2) 65-85.

Gelabert, L., Labandeira, X., Linares, P., 2011. An ex-post analysis of the effect of renewables and cogeneration on Spanish electricity prices. Energy Econ. 33 (S1), S59-S65.

Glachant, J., Ruester, S., 2014. The EU internal electricity market: done forever? Util Policy 30, 1-7.

Gonzalo, J., 1994. Five alternative methods of estimating long-run equilibrium relationships. J. Econ. 60 (1), 203-233.

Gullì, F., 2008. Modelling the short-run impact of 'carbon trading' on the electricity sector. In: Markets for Carbon and Power Pricing in Europe: Theoretical Issues and Empirical Analyses. Edward Edgar Publishing, Cheltenham, UK, pp. 36-79.

Harbo, I., Johansen, S., Nielsen, B., Rahbek, A., 1998. Asymptotic inference on cointegrating rank in partial systems. J. Bus. Econ. Stat. 16 (4), 388-399.

Honkatukia, J., Malkonen, V., Perrels, A., 2006. Impacts of the European Emissions Trade System on Finnish Wholesale Electricity Prices. Government Institute for Economic Research, Helsinki. VATT Discussion Paper No 405.

Johansen, S., 1991. Estimation and hypothesis testing of cointegration vectors in gaussian vector autoregressive models. Econometrica 59 (6), 1551-1580.

Johansen, S., 1995. Likelihood-based Inference in Cointegrated Vector Autoregressive Models. Oxford University Press, New York.

Jouvet, P., Solier, B., 2013. An overview of $\mathrm{CO}_{2}$ cost pass-through to electricity prices in Europe. Energy Policy 61, 1370-1376.

Juselius, K., 2006. The cointegrated VAR model: methodology and applications. Oxford University Press, Oxford.

Koch, N., Fuss, S., Grosjean, G., Edenhofer, O., 2014. Causes of the EU ETS price drop: recession, $\mathrm{CDM}$, renewable policies or a bit of everything? new evidence. Energy Policy 73, 676-685.

Kwiatkowski, D., Phillips, P., Schmidt, P., Shin, Y., 1992. Testing the null hypothesis of stationarity against the alternative of a unit root: how sure are we that economic time series have a unit root? J. Econ. 54, 159-178.

Lanne, M., Lutkepohl, H., Saikkonen, P., 2002. Comparison of unit root tests for time series with level shifts. J. Time Ser. Anal. 23 (6), 667-685.

Lise, W., Sijm, J., Hobbs, F., 2010. The impact of the EU ETS on prices, profits and emissions in the power sector: simulation results with the COMPETES EU20 model. Environ. Resour. Econ. 47 (1), 23-44.

MacKinnon, J., 1996. Numerical distribution functions for unit root and cointegration tests. J. Appl. Econ. 11 (6), 601-618.

Mackinnon, J., Haug, A., Michelis, L., 1999. Numerical distribution functions of likelihood ratio tests for cointegration. J. Appl. Econ. 14 (5), 563-577.

Mansanet-Bataller, M., Pardo, A., Valor, E., 2007. $\mathrm{CO}_{2}$ prices, energy and weather Energy J. 28 (3), 73-92.

Mjelde, J., Bessler, D., 2009. Market integration among electricity markets and their major fuel source markets. Energy Econ. 31 (3), 482-491.

Mohammadi, H., 2009. Electricity prices and fuel costs: long-run relations and short-run dynamics. Energy Econ. 31 (3), 503-509.

Moutinho, V., Vieira, J., Moreira, A., 2011. The crucial relationship among energy commodity prices: evidence from the spanish electricity market. Energy Policy 39 (10), 5898-5908.

Osterwald-Lenum, M., 1992. A note with quantiles of the asymptotic distribution of the maximum likelihood cointegration rank test statistics. Oxf. Bull. Econ. Stat. 54 (3), $461-471$.

Pesaran, M., Shin, Y., Smith, R., 2000. Structural analysis of vector error correction models with exogenous I(1) variables. J. Econ. 97 (2), 293-343.

Pinho, C., Madaleno, M., 2011. $\mathrm{CO}_{2}$ emission allowances and other fuel markets interaction. Environ. Econ. Policy Stud. 13 (3), 259-281.

Sijm, J., Bakker, S., Chen, Y., Harmsen, H., Lise, W., 2005. CO 2 Price Dynamics: the Implications of EU Emissions Trading for the Price of Electricity. ECN - Energy Research Centre of the Netherlands, Amsterdam.

Sijm, J., Neuhoff, K., Chen, Y., 2006. $\mathrm{CO}_{2}$ cost pass through and windfall profits in the power sector. Clim. Policy 6 (1), 49-72.

Sijm, J., Hers, S., Lise, W., Wetzelaer, B., 2008. The Impact of the EU ETS on Electricity Prices - Final Report to DG Environment of the European Commission. ECN Energy Research Centre of the Netherlands, Amsterdam.

Silva, P., Soares, I., 2008. EU spot prices and industry structure: assessing electricity market integration. Int. J. Energy Sect. Manag. 2 (3), 340-350.

Thoenes, S., 2011. Understanding the Determinants of Electricity Prices and the Impact of the German Nuclear Moratorium in, vol. 2011. Institute of Energy Economics, University of Cologne, Cologne. EWI Working Paper No 11/06.

Van den Bergh, K., Delarue, E., D'haeseleer, W., 2013. Impact of renewables deployment on the $\mathrm{CO}_{2}$ price and the $\mathrm{CO}_{2}$ emissions in the European electricity sector. Energy Policy 63, 1021-1031. 